\title{
GESTÃO DA INFORMAÇÃO NO BLOG DE OLHO NA $\mathrm{Cl}$
}

\section{GESTIÓN DE LA INFORMACIÓN EM BLOG DE OLHO NA CI}

\begin{abstract}
Isa Maria Freire - isafreire@globo.com Doutora em Ciência da Informação pela Universidade Federal do Rio de Janeiro (UFRJ). Docente do Programa de Pós-Graduação em Ciência da Informação da Universidade Federal da Paraíba (UFPB).

Raimundo Nonato Ribeiro dos Santos - nonatobiblio@gmail.com Mestrando no Programa de Pós-Graduação em Ciência da Informação da Universidade Federal da Paraíba (UFPB).

Breno Oliveira Nóbrega do Nascimento - breno.on@gmail.com Graduando em Biblioteconomia na Universidade Federal da Paraíba (UFPB). Bolsista do Conselho Nacional de Desenvolvimento Científico e Tecnológico (CNPq).
\end{abstract}

RESUMO

Introdução: Os meios de comunicação de massa, das tecnologias digitais e da rede Internet transformaram o cotidiano dos seres humanos. Com sua popularização, passou-se a utilizar estes meios de comunicação disponíveis para compartilhar informações, tanto no ambiente real quanto no espaço virtual, lidando com aspectos de produção e comunicação da informação. Essas questões dizem respeito à temática da gestão da informação.

Objetivo: Analisar o Blog De Olho $\mathrm{Na} \mathrm{Cl}$ na perspectiva da gestão da informação e dos estudos acerca dos agregados de informação.

Metodologia: Realizou-se um levantamento documental na literatura em Ciência da Informação sobre os estudos desenvolvidos acerca dos agregados de informação. Analisa o Blog De Olho $\mathrm{Na} \mathrm{Cl}$ nesta perspectiva, alinhada as pesquisas de gestão da informação desenvolvidas na área de Ciência da Informação.

Resultados: O Blog De Olho $\mathrm{Na} \mathrm{Cl}$ atua como um agregado de informação, cumprindo as duas funções indicadas pela literatura: produção e transferência de informação. 
Breno Oliveira Nóbrega do Nascimento; Raimundo Nonato Ribeiro dos Santos; Isa Maria

Freire

Gestão da informação no blog de olho na Cl

Conclusões: A informação torna-se um ponto central entre Política e Gestão no ambiente governamental e institucional. O blog $\mathrm{De}$ Olho $\mathrm{Na} \mathrm{Cl}$ é uma iniciativa em prol do acesso livre à informação, um agregado de informações onde as funções produção e transferência da informação se harmonizam e criam oportunidades de compartilhamento de novas informações. Dessa forma, se estabelece um ciclo virtuoso de busca, produção e distribuição da matéria-prima mais importante na sociedade contemporânea: a informação.

Palavras-chave: Gestão da informação. Agregados de informação. Comunicação da informação. Blog De Olho Na Cl.

\section{INTRODUÇÃO}

O Blog De Olho $\mathrm{Na}$ Cl tem o propósito de compartilhar informações voltadas para os pesquisadores, profissionais e estudantes da informação, contribuindo para divulgação de oportunidades de formação continuada e desenvolvimento de estudos e pesquisas na área de Ciência da Informação e afins. O projeto de publicação do blog De Olho $\mathrm{Na} \mathrm{Cl}$ resulta da integração de projetos de pesquisa em níveis de graduação e pós-graduação no âmbito do Laboratório de Tecnologias Intelectuais (Lti) do Departamento de Ciência da Informação, em parceria com o Programa de Pós-Graduação em Ciência da Informação da Universidade Federal da Paraíba e com apoio do CNPq - Edital Universal e Programa Interinstitucional de Bolsas de Iniciação Científica.

Neste artigo analisa-se o blog De Olho $\mathrm{Na} \mathrm{Cl}$ na perspectiva da gestão da informação, utilizando-se a abordagem dos agregados de informação, proposta e discutida por Barreto (1994; 1996; 1999).

A abordagem toma como pressuposto o fato de que o uso dos meios de comunicação de massa e, mais recentemente, das tecnologias digitais e da rede Internet, transformaram o cotidiano dos seres humanos. Com a popularização desses recursos, as pessoas passam a utilizar os meios de comunicação disponíveis para compartilhar informações, das mais diversas formas e formatos, dos mais diversos tipos e finalidades, para os mais diversos grupos de usuários potenciais.

Contudo, quando se fala em compartilhar informações, tanto no ambiente real quanto no espaço virtual, trata-se de lidar com aspectos de produção e comunicação 
Breno Oliveira Nóbrega do Nascimento; Raimundo Nonato Ribeiro dos Santos; Isa Maria Freire

Gestão da informação no blog de olho na Cl

da informação, questões essas que dizem respeito à temática da gestão da informação.

\section{ABORDAGEM DA GESTÃO DA INFORMAÇÃO}

Em uma sociedade em que informação, conhecimento, criatividade e inovação são primordiais, paulatinamente são lançados desafios à comunidade científica. A relevância que a informação assumiu na atual sociedade coloca em pauta questões sobre a sua natureza, sua conceituação científica e os benefícios que pode trazer ao indivíduo, ao seu grupo e à sociedade (BARRETO, 1994).

Assim como diferentes áreas do conhecimento apresentam práticas e comportamentos peculiares, incluindo seus respectivos cientistas (ZIMAN, 1979), a natureza da informação proveniente dessas mesmas áreas agrega características inerentes à sua origem e aos usuários a que se destinam. Saracevic alerta para a importância da "[...] integração e inter-relação entre produtores de conhecimentos, instituições de um modo geral, bibliotecas e serviços de informação, seus mecanismos e usuários [...]" (SARACEVIC, 1996, p. 58).

Nesse contexto, a gestão da informação é uma das preocupações e desafios que transparecem nos artigos científicos na área da Ciência da Informação e em outras áreas do conhecimento. Cianconi (1999) detalha em seu artigo os aspectos que contemplam a informação considerando o processo da gestão: planejamento, seleção, coleta, análise, organização, otimização dos fluxos, normalização, disponibilização para uso e avaliação (CIANCONI, 1999, p. 33).

Outros autores conhecidos que abordam a temática da gestão da informação, como McGee e Prusak (1994) e Davenport (1998), referem-se à gestão da informação como processo para identificar as necessidades de informação, coletar, classificar, armazenar, tratar e disponibilizar. Ressalte-se que esses autores atuam no segmento empresarial, isto é, consideram a informação para negócios.

Esta pesquisa, contudo, teve como base o conceito de Gestão da Informação, sob o enfoque da Ciência da Informação, definido pelo Institute of Information Scientists (2001) e citado por Marchiori (2002, p. 75), onde esclarece que a gestão da informação: 
[...] em sua essência [...] se ocupa do estudo da informação em si, isto é, a teoria e a prática que envolve [sic] sua criação, identificação, coleta, validação, representação, recuperação e uso, tendo como princípio o fato de que existe um produtor/consumidor de informação que busca, nesta, um "sentido" e uma "finalidade" [...]. Neste contexto, tanto os processos administrativos, como a utilização de tecnologias são mecanismos facilitadores para otimização de processos que levam, idealmente, à comunicação efetiva da informação entre indivíduos e grupos. Assim, a gestão da informação tem, por princípio, enfocar o indivíduo (grupos ou instituições) e suas "situações-problema" no âmbito de diferentes fluxos de informação, os quais necessitam de soluções criativas e custo/efetivas [...].

Marchiori (2002, p. 75-77) contempla não somente as etapas da Gestão da Informação, mas também destaca as tecnologias, os indivíduos e os procedimentos que a aproximam da Ciência da Informação. A autora esclarece sobre os conhecimentos e contextos que envolvem o processo integral de Gestão dos recursos de informação nas organizações, assim descritos:

a) Planejamento: ações que vão desde a identificação das necessidades até a geração de produtos e serviços;

b) Comunicação: teorias e modelos de aplicação;

c) Gerência da informação e sistemas de controle: métodos de monitoramento do fluxo e tecnologias que apoiem o fluxo;

d) Gerência de recursos humanos: perfil e atividades dos atores no processo de gestão;

e) Gerência de recursos financeiros: da previsão à execução do orçamento;

f) Promoção, vendas e marketing: análise do ambiente externo em prol do produto ou serviço;

g) Contexto político, ético, social e legal: situações políticas que englobam atividades humanas em geral, governo e informação em particular, abrangendo questões éticas e legais e temas correlatos;

h) Sistemas computacionais: processos no desenvolvimento de hardware e softwares;

i) Telecomunicações: questões de acesso e conectividade;

j) Aplicações da tecnologia da informação: coleta, armazenagem e 
Breno Oliveira Nóbrega do Nascimento; Raimundo Nonato Ribeiro dos Santos; Isa Maria Freire

Gestão da informação no blog de olho na Cl

recuperação da informação, videotexto, telex, reconhecimento de voz, digitalização, tecnologias de discos compactos, telecomunicações, métodos de publicação eletrônica e de disseminação de documentos via redes;

k) Meio ambiente: princípios de ergonomia, proteção de dados, copyright, pirataria, criptografia etc. (MARCHIORI, 2002, p. 75-77).

Nesse sentido, apresenta-se uma discussão a partir dos estudos de Barreto (1994; 1996; 1999) sobre os agregados de informação na sociedade contemporânea, modelo conceitual adotado no presente trabalho, onde se toma como objeto de pesquisa o Blog De Olho $\mathrm{Na} \mathrm{Cl}$.

\section{OS AGREGADOS DE INFORMAÇÃO DE BARRETO}

Diversos conceitos para a informação caracterizam o fenômeno como a adequação de um processo comunicativo que se efetiva entre um emissor e um receptor da mensagem, como discorre Freire (1998, p. 103):

É no espaço social, político e econômico que ocorre o fenômeno da produção e circulação da informação [...] através de um processo de comunicação social que engloba uma fonte geradora de informação (um emissor), os canais de transmissão do "texto e sua estrutura" e (um receptor) usuário da informação.

É nessa perspectiva que Barreto $(1994,1996,1999)$ apresenta sua abordagem dos agregados de informação. Neste modelo, a observação e a discussão de características e qualidades referentes ao fenômeno da informação acontecem entre seres humanos, habitando um determinado espaço social, político e econômico, em que existem uma fonte geradora ou um emissor de informação, um canal de transferência e um destinatário ou receptor de uma mensagem. Para Barreto (1994, p. 2):

[...] a informação é qualificada como um instrumento modificador da consciência e da sociedade como um todo. Aqui a informação é qualificada como um instrumento modificador da consciência do homem e de seu grupo. [...] A informação, quando adequadamente 
Breno Oliveira Nóbrega do Nascimento; Raimundo Nonato Ribeiro dos Santos; Isa Maria Freire

Gestão da informação no blog de olho na Cl

assimilada, produz conhecimento, modifica o estoque mental de informações do indivíduo e traz benefícios ao seu desenvolvimento e ao desenvolvimento da sociedade em que ele vive.

Dessa forma, o autor percebe a informação como 'estrutura significante', ou seja, como agente mediador na produção do conhecimento, com a competência de gerar conhecimento para o indivíduo e seu grupo.

Assim surge a questão de como se trabalhar com a informação enquanto estrutura significante, no sentido de direcioná-la ao seu propósito de produtora de conhecimento para a sociedade e como produzir, organizar, controlar e distribuir a informação de uma maneira correta política e socialmente.

Barreto (1996) apresenta o modelo conceitual dos agregados de informação, local de armazenamento das estruturas de informação. Para Barreto (1996, p. 3), os agregados de informação:

[...] representam os diferentes estoques que nossas estruturas significantes de informação podem assumir, tais como, acervos em geral em bibliotecas ou outro centro de informação/documentação, bases de dados ou estoques em qualquer outro meio eletrônico, redes de informação.

Destarte, Barreto (1996) propõe, em sua abordagem, duas funções básicas para os agregados de informação: (a) produção da informação e (b) transferência da informação. O autor caracterizou as duas funções de um agregado de informação, como segue:

A função de produção de informação se caracteriza por:

1) acumular estoques estáticos de informação [...]; 2) possuir uma racionalidade técnica, com padrões estabelecidos internacionalmente e homogêneos no tratamento e reformação da informação; 3) se orientar por produtividade de espaço e custo a sua eficácia é indicada por medidas de revocação e precisão; 4) [...] é parte de um sistema maior que é o sistema de produção de conhecimento; 5) as medidas de eficácia, revocação e precisão são parciais em relação ao sistema maior, são ultrapassadas em relação às atuais tecnologias de informação;

[...]

A função de transferência ou distribuição da Informação se caracteriza por:

a) possuir uma racionalidade contextual e cognitiva, relacionada a um determinado espaço social específico. É, na interação da função de transferência com uma determinada realidade, que se realiza a 
produção do conhecimento, na qual acontece a essência do fenômeno da informação, resultado da passagem de um estado de percepção (USO) da informação para a sensação provocada pela informação, uma interiorização individualizada (assimilação) e a geração de conhecimento. b) a relação informação/conhecimento substitui a relação revocação/precisão, uma é quantitativa a outra é qualitativa (BARRETO, 1996, p. 4, grifo nosso)

Assim, a função de produção de informação abarca atividades relacionadas com a reunião, a seleção, o processamento e o armazenamento da informação, por exemplo, voltadas para a formação dos estoques de informação, que são quantidades estáticas de informação armazenadas em acervos de bibliotecas, arquivos, museus, bases de dados, redes ou de sistemas de informação. Apesar desses estoques de informação serem indispensáveis ao processo de geração de conhecimento, eles são estáticos e por si só não efetivam este processo.

Neste processo de geração de conhecimento, a função de transferência da informação contempla a comunicação, aceitação, uso e assimilação da informação, criando conhecimento no indivíduo receptor e em sua ambiência. Portanto, em um agregado de informação a função de produção refere-se ao armazenamento e organização de estoques de informação, e a função de transferência da informação objetiva transmitir mensagens adequadamente para determinados grupos de usuários, na sociedade.

Essas funções vinculam-se, respectivamente, ao processo de oferta e demanda da informação em uma determinada conjuntura informacional. Um estoque de informação pode representar a oferta de informação no âmbito de um determinado contexto informacional e para determinados grupos de usuários. Por sua vez, a função de transferência efetiva a distribuição da informação armazenada e organizada, com a intenção de atender à demanda existente, explícita ou ainda não explicitada.

Dessa forma, as estruturas significantes que constituem os estoques de informação em um agregado podem ser construídas por meio de ações políticas e técnico-científicas, ou gerenciais, no contexto da produção e transferência de estoques de informação relevantes para a produção do conhecimento.

Apresenta-se a seguir o blog De Olho $\mathrm{Na} \mathrm{Cl}$, na perspectiva dos agregados de informação. 
Breno Oliveira Nóbrega do Nascimento; Raimundo Nonato Ribeiro dos Santos; Isa Maria Freire

Gestão da informação no blog de olho na Cl

\section{AMBIENTE DE ESTUDO: DE OLHO NA CI}

Atualmente, os blogs se tornaram importantes tecnologias intelectuais digitais para a comunicação global. No contexto dos profissionais da informação, a Internet, no contexto da rede, tem uma participação fundamental no auxílio à disseminação de informação em todos os campos do conhecimento.

Com a popularização desses recursos, utiliza-se os meios de comunicação disponíveis para compartilhar informações, das mais diversas formas e formatos, dos mais diversos tipos e finalidades, para os mais diversos e diversificados grupos de usuários potenciais. Nesse contexto, as mídias sociais, mais especificamente os blogs, passaram por adequações de acordo com a evolução da Web, evoluindo de diários pessoais, nos quais eram depositados opiniões, comentários e experiências individuais, para assumir uma função informativa, como se pode observar nas interfaces dos jornais na Web (FREIRE; LIMA; COSTA JÚNIOR, 2012).

O Blog De Olho $\mathrm{Na} \mathrm{Cl}$ foi criado em 13 de agosto de 2010, no âmbito do periódico secundário Revista Pesquisa Brasileira em Ciência da Informação e Biblioteconomia (PBCIB). O blog surgiu com 0 intuito de promover maior aproximação entre o público-alvo da PBCIB, os profissionais da informação, e os acontecimentos nos campos da Ciência da Informação, Biblioteconomia, Arquivologia, Museologia e Memória Social.

A PBCIB e o Blog De Olho $\mathrm{Na} \mathrm{Cl}$ são executados no âmbito da rede de projetos Laboratório de Tecnologias Intelectuais (LTI) da Universidade Federal da Paraíba (UFPB) e recebe apoio do Programa Institucional de Bolsas de Iniciação Científica do CNPq e da Coordenação de Aperfeiçoamento de Pessoal de Nível Superior (CAPES). O blog possui registro no Internet Blog Serial Number (IBSN) de número 383-6651-52-4 (Figura 1).

Atualmente a equipe do blog é formada por um Editor (bibliotecário e mestrando em Ciência da Informação), responsável pela seleção e elaboração das notícias, e dois editores-adjuntos (graduandos em Biblioteconomia, bolsistas CNPq PIBIC) responsáveis pelas postagens das notícias e divulgação nas mídias sociais.

O blog De Olho $\mathrm{Na} \mathrm{Cl}$ é construído e disponibilizado pela plataforma Webnode, especializada em construção de websites e blogs, funcionando à base da 
Breno Oliveira Nóbrega do Nascimento; Raimundo Nonato Ribeiro dos Santos; Isa Maria Freire

Gestão da informação no blog de olho na Cl

tecnologia drag-and-drop (arraste e largue). A plataforma Webnode disponibiliza páginas pré-formatadas com recursos básicos para a construção do blog, editoração de notícias, comentários, links, imagens e vídeos. A interface do blog De Olho $\mathrm{Na} \mathrm{Cl}$ pode ser vista na Figura 1:

Figura 1 - Interface gráfica do blog De Olho $\mathrm{Na} \mathrm{Cl}$

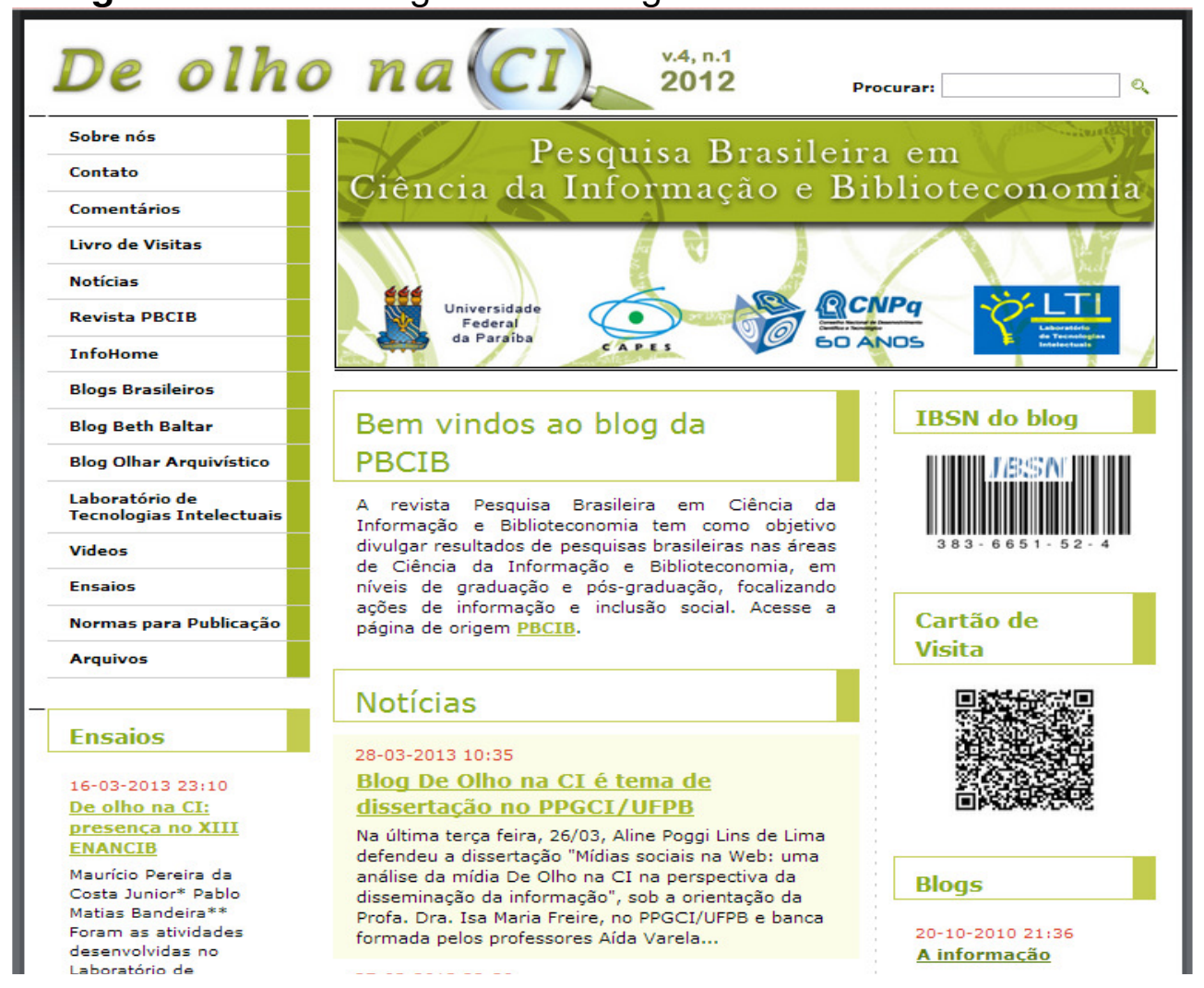

Fonte: Pesquisa Brasileira em Ciência da Informação e Biblioteconomia (2013).

A seguir, descreve-se a seções que constituem o menu de serviços do blog, localizado à esquerda da interface:

a. Sobre nós: Descrevendo a finalidade, objetivos e público-alvo do blog. Descrição da Revista Pesquisa Brasileira em Ciência da Informação e Biblioteconomia (PBCIB);

b. Contato: Local disponível para contato direto com editores via e-mail;

c. Comentários: Espaço onde os usuários podem expressar suas opiniões, sugestões e experiências;

d. Livro de visitas: Campo reservado para armazenamento de todos os comentários disponibilizados no blog; 
Breno Oliveira Nóbrega do Nascimento; Raimundo Nonato Ribeiro dos Santos; Isa Maria Freire

Gestão da informação no blog de olho na Cl

e. Notícias: Postagens de notícias sobre eventos, congressos, seminários, conferências, concursos, e todo que estiver relacionado às áreas de Biblioteconomia, Ciência da Informação, Arquivologia e Museologia;

f. Ensaios: Espaço reservado à publicação e compartilhamento de relatos de experiências ou pontos de vista, por profissionais da informação;

g. Revista PBCIB: Link para a revista Pesquisa Brasileira em Ciência da Informação e Biblioteconomia, responsável pela edição do blog;

h. Infohome e Blog Beth Baltar: Redirecionamento para estes dois websites que possuem ligação direta com o blog De Olho Na Cl;

i. Blogs: Arquivo com descrição e links para blogs na área de Ciência da Informação e afins, com intuito de manter uma rede de contatos de interesses para os leitores e para o blog;

j. Laboratório de Tecnologias Intelectuais - LTi: A revista PBCIB e o blog De Olho $\mathrm{Na} \mathrm{Cl}$ fazem parte da rede de projetos LT $i$ da UFPB;

k. Vídeos: Divulgação de vídeos relacionados à $\mathrm{Cl}$ e áreas afins, atuando em colaboração com o LTi;

I. Normas para publicação de Ensaio: Diretrizes para autores que desejam publicar no blog;

m. Arquivos: Organização, por volumes e fascículos, das Notícias e Ensaios publicados e quantidade de visitas, no período PESQUISA BRASILEIRA EM CIÊNCIA DA INFORMAÇÃO E BIBLIOTECONOMIA (2013).

Nesse contexto, o blog De Olho $\mathrm{Na} \mathrm{Cl}$ atua como um agregado de informação, cumprindo as duas funções propostas na literatura - produção e transferência de informação, descritas por Barreto (1996, p. 4) como segue:

Função produção: busca e elaboração de notícias, normas editoriais para ensaios, arquivos para organização de conteúdos, descrição das fontes de pesquisas, organização dos arquivos, produção de tags (tipos de notícias), lista de blogs;

Função transferência/comunicação: publicação de notícias, ensaios, arquivos e lista de blogs, mídias sociais Facebook e Twitter, mapa de acessos (locais, visitantes únicos e visitas, páginas mais visitadas, tempo de permanência e outros indicadores do uso do blog). 
Breno Oliveira Nóbrega do Nascimento; Raimundo Nonato Ribeiro dos Santos; Isa Maria Freire

Gestão da informação no blog de olho na Cl

Nielsen (2007) destaca a necessidade para que os agregados de informação organizem a informação, resultando em mais poder do que as pessoas que originalmente produziram a informação, especialmente se forem adicionadas camadas de valor pela organização da informação de maneira útil. Nesse campo de pesquisa, aplicam-se as palavras de Freire e Freire (1998), que informam: "[É possível] tirar proveito do grande volume de informação, [re] elaborando-a de acordo com seu potencial de transformação para um dado usuário".

A produção e postagem de notícias, no blog, ocorrem diariamente. São elaboradas a partir de recebimento e/ou busca de pautas confiáveis enviados por meio de listas de discussão, como a lista da ANCIB, do EDICIC, bem como os sites governamentais, as mídias sociais e pessoais de pesquisadores e profissionais. A notícia contém as informações necessárias aos leitores, fonte de pesquisa e/ou link da página que originou a notícia.

Foi com essa política de criar demanda a partir da oferta seletiva e criteriosa de informações de interesse para profissionais da área de Ciência da Informação e afins, que o blog De Olho $\mathrm{Na} \mathrm{Cl}$ conseguiu, em dois anos e meio de publicação, a marca de 122 mil visitantes únicos, até 19 de novembro de 2013.

A seguir, apresenta-se no Quadro 1 os dados das funções produção e transferência, consolidados a partir dos arquivos do blog:

Quadro 1 - Produção e visitas no período de agosto/2010 a junho/2013

\begin{tabular}{|c|c|c|}
\hline Ensaios & Notícias & Visitas \\
\hline \hline 51 & $\mathbf{2 . 5 7 2}$ & $\mathbf{5 2 1 . 4 4 3}$ \\
\hline
\end{tabular}

Fonte: Pesquisa Brasileira Em Ciência Da Informação E Biblioteconomia (2013).

No Gráfico 1, a seguir, estão descritos os números de visitantes únicos mensais (usuários contabilizados uma única vez, no primeiro acesso). O maior número de visitantes que o blog teve desde sua criação, ocorreu no mês de abril de 2013 e corresponde a 6.526 visitantes. 
Breno Oliveira Nóbrega do Nascimento; Raimundo Nonato Ribeiro dos Santos; Isa Maria Freire

Gestão da informação no blog de olho na Cl

Gráfico 1 - Gráfico de visitantes únicos do blog De Olho Na Cl.

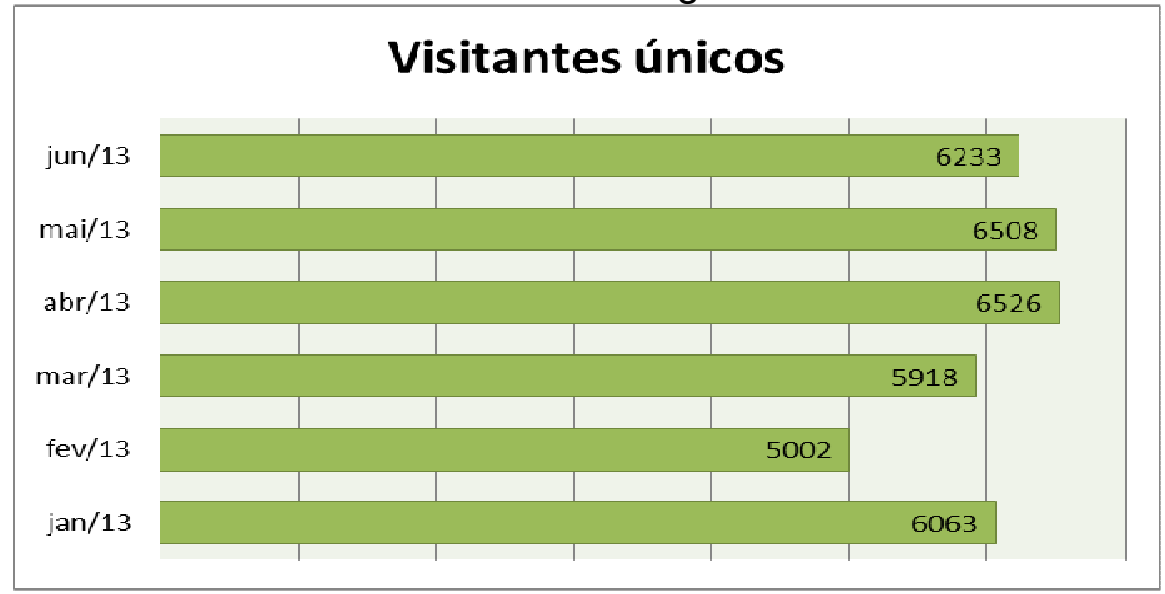

Fonte: Autor.

O Gráfico 2 mostra as páginas visitadas por mês, com um exponencial aumento no mês de janeiro de 2013: 213.943 páginas do blog foram acessadas. Este número está de acordo ao número de visitantes únicos que o blog teve no período, apontando que nossos visitantes navegam por grande quantidade de páginas de nosso blog quando o acessam. Estes números podem ser atribuídos a periodicidade que o blog apresenta na sua atualização, publicando notícias diariamente e chegando a números similares mensalmente, fazendo com que o número de páginas visitados acompanhem o padrão de desempenho.

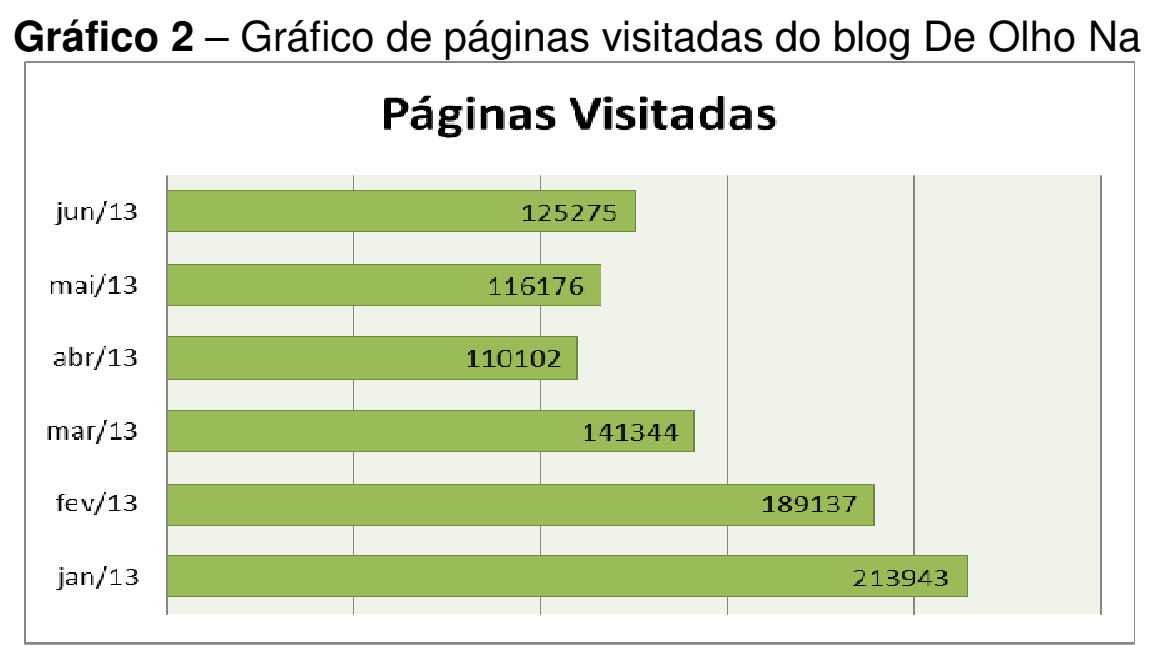

Fonte: Autor.

Na Figura 3, observa-se o número geral de visitantes únicos e o acesso mundial ao blog, por país, destacando-se o Brasil e os estados da federação: 
Breno Oliveira Nóbrega do Nascimento; Raimundo Nonato Ribeiro dos Santos; Isa Maria Freire

Gestão da informação no blog de olho na Cl

Figura 3 - Total e distribuição geográfica de visitantes únicos (Dados de 13/06/2011 a 19/11/2013)

\begin{tabular}{|c|c|c|c|}
\hline Q Brazil (BR) & 18,387 & 虽 D United States (US) & 510 \\
\hline Paraiba & 4,495 & $\triangle D$ Czech Republic (CZ) & 153 \\
\hline Sao Paulo & 3,175 & $\square \triangleright$ portugal (PT) & 126 \\
\hline Rio de Janeiro & 1,607 & D Spain (ES) & 112 \\
\hline Minas Gerais & 1,210 & [I]D France (FR) & 88 \\
\hline Pernambuco & 950 & $\square D$ Germany (DE) & 23 \\
\hline $\begin{array}{l}\text { Ceara } \\
\text { Rio Grande do Sul }\end{array}$ & $\begin{array}{l}940 \\
549\end{array}$ & $\square D$ Italy (IT) & 19 \\
\hline Rio Grande do Norte & $\begin{array}{l}549 \\
534\end{array}$ & {$[*] \triangleright$ Canada (CA) } & 18 \\
\hline Distrito Federal & 449 & $\square D$ Russian Federation (RU) & 12 \\
\hline Bahia & 364 & $\square D$ Chile $(C L)$ & 9 \\
\hline
\end{tabular}

Fonte: ClustrMap (2013).

Nota: No domínio anterior, dezembro de 2010 e junho de 2011, o blog teve 2.931 visitantes únicos cadastrados.

Destarte, a função transferência, em sua interface de comunicação mediante redes sociais virtuais, vem criando novos espaços de divulgação das notícias do blog e maior interação com os usuários, como mostra a Figura 4, a seguir, a respeito da fanpage do Blog no Facebook:

Figura 4 - Números alcançados no Facebook no período de 28/04/2013 a $26 / 07 / 2013$

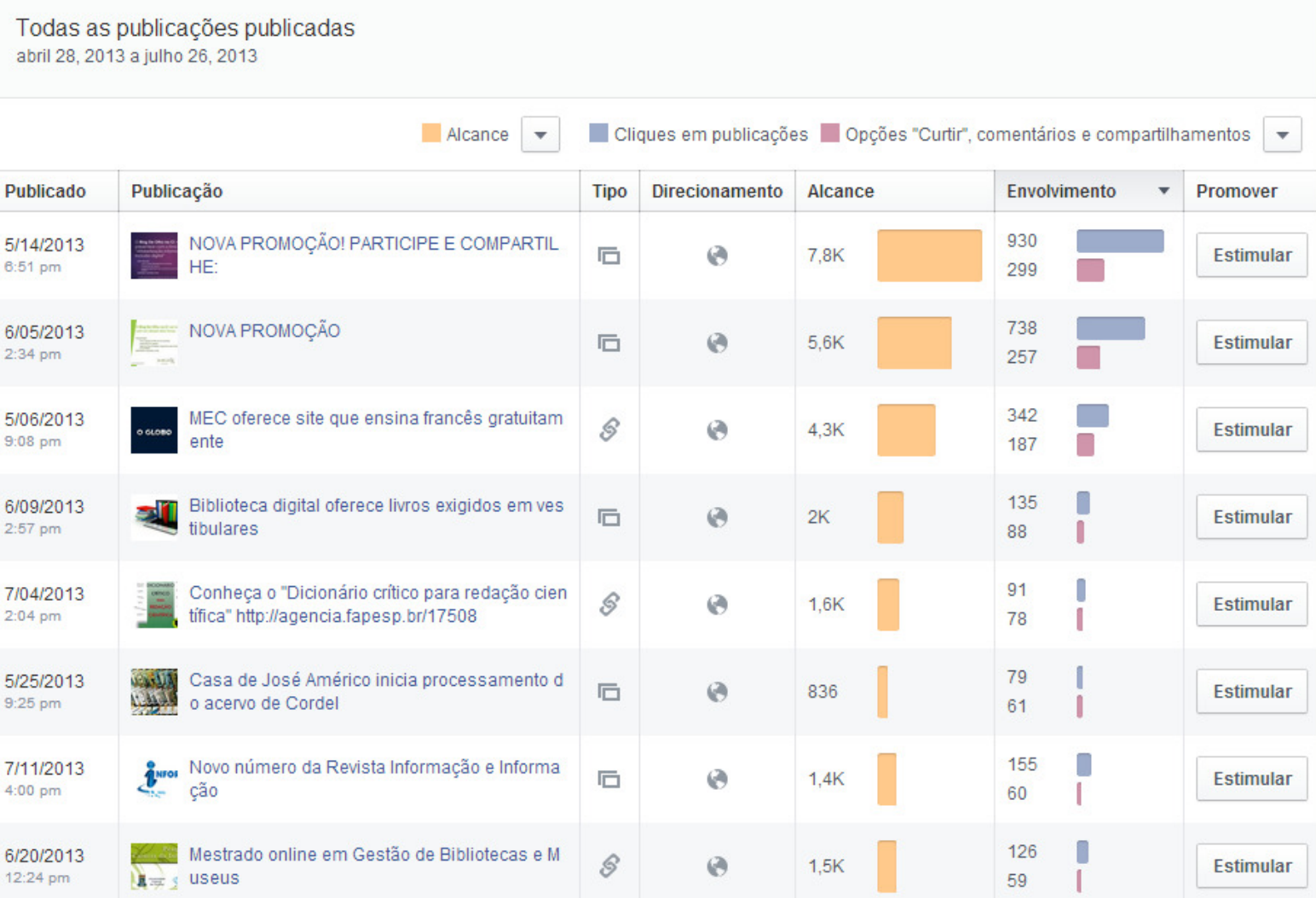

Fonte: Relatório de acompanhamento. Dados referentes ao perído de 28 de abril a 26 de julho de 2013.

Inf. Inf., Londrina, v. 19, n. 1, p. 95 - 111, jan./abr. 2014. http:www.uel.br/revistas/informacao/ 
Breno Oliveira Nóbrega do Nascimento; Raimundo Nonato Ribeiro dos Santos; Isa Maria Freire

Gestão da informação no blog de olho na Cl

Destaca-se a coluna denominada Envolvimento, que refere-se a quantidade de pessoas que viram a publicação. Em uma utilização mais aprimorada da mídia social virtual Facebook, o blog passou a interagir com o público-alvo mediante a estratégia de postar imagens para representar o conteúdo textual da notícia. Essa ação trouxe, em fevereiro de 2013, mais de 4 mil usuários únicos para a página De Olho $\mathrm{Na} \mathrm{Cl}$ no Facebook, com reflexos no acesso e uso do blog.

\section{CONSIDERAÇÕES FINAIS}

Diante desse quadro, observa-se que o blog De Olho $\mathrm{Na} \mathrm{Cl}$, objeto deste artigo, se diferencia dos blogs enquanto somente diários pessoais, seja por sua definição como canal de comunicação da revista $\mathrm{PBCIB}$, ou por sua finalidade de prestação de serviços para um determinado público-alvo (profissionais da informação), ou por suas características de canal de comunicação científica, mediante publicação de ensaios inéditos e de fonte referencial com a lista de blogs da área da Ciência da Informação.

Conforme os dados apresentados, o Blog De Olho $\mathrm{Na} \mathrm{Cl}$ constitui-se em relevante agregado de informações, credenciada por seu registro IBSN. Como um produtor de informação, produz diariamente notícias, ensaios e mantém atualizada lista de blogs brasileiros em Ciência da Informação, fornecendo aos profissionais da informação e estudantes material já filtrado para sua formação e educação continuada.

Para transferir essa informação, tem investido nas mídias sociais Twitter e Facebook reproduzindo os links do blog e estabelecendo um fluxo entre seus leitores. Cada vez mais o público-leitor acessa as mídias sociais, compartilha e adquire informações relevantes para sua vida acadêmica e profissional. Os dados revelam o aumento no acesso às páginas, principalmente nas abas Notícias e Ensaios, e o retorno do público-leitor em busca de novas informações, seja elas cursos, congressos, eventos, lançamentos de livros, novas edições de revistas científicas, etc. $\mathrm{Na}$ atual sociedade, a informação, o conhecimento, a criatividade e a inovação tornam-se desafios lançados à comunidade científica.

Assim, o blog De Olho $\mathrm{Na} \mathrm{Cl}$ nos parece operar como um agregado de 
Breno Oliveira Nóbrega do Nascimento; Raimundo Nonato Ribeiro dos Santos; Isa Maria Freire

Gestão da informação no blog de olho na Cl

informações, onde as funções produção e transferência da informação se complementam e criam oportunidades de compartilhamento de novas informações. Num ciclo virtuoso de busca, produção e distribuição da matéria-prima mais importante na sociedade contemporânea: a informação.

\section{REFERÊNCIAS}

BARRETO, Aldo de Albuquerque. A oferta e a demanda da informação: condições técnicas, econômicas e políticas. Ciência da Informação, Brasília, v. 28, n. 2, 1999. Disponível em: <http://revista.ibict.br/ciinf/index.php/ciinf/article/view/298/264>. Acesso em: 18 nov. 2013.

BARRETO, Aldo de Albuquerque. A eficiência técnica e econômica e a viabilidade de produtos e serviços de informação. Ciência da Informação, Brasília, v. 25, n. 3, 1996. Disponível em: <http://revista.ibict.br/ciinf/index.php/ciinf/article/view/466/425>. Acesso em: 18 nov. 2013.

BARRETO, Aldo de Albuquerque. A questão da informação. São Paulo em Perspectiva, São Paulo v. 8, n. 4, 1994.

CIANCONI, Regina. Gestão da informação na sociedade do conhecimento. Brasília: SENAI, 1999.

CLUSTRMAPS. Disponível em:<http://www2.clustrmaps.com/pt/counter/maps.php?url=http://pbcib.webnode.co m.br>. Acesso em: 18 nov. 2013.

DAVENPORT, Thomas. Ecologia da informação: por que só a tecnologia não basta para o sucesso na era da informação. São Paulo: Futura, 1998.

FREIRE, Gustavo Henrique Construção de um instrumento para a comunicação da informação sobre saúde. 1998. Dissertação (Mestrado em Ciência da Informação) - UFRJ/ECO/IBICT, Rio de Janeiro, 1998.

FREIRE, Isa Maria; LIMA, Aline Poggi Lins de; COSTA JUNIOR, Maurício Pereira da. Mídias sociais na web: de olho na $\mathrm{Cl}$ para capacitação acadêmica e profissional. Biblionline, João Pessoa, v. 8, n. esp., p. 175-184, 2012. Disponível em: <http://periodicos.ufpb.br/ojs2/index.php/biblio/article/view/14202/8108>. Acesso em: 18 nov. 2013.

FREIRE, Isa Maria; FREIRE, Gustavo Henrique. Navegando a literatura: o hipertexto como instrumento de ensino. Transinformação, Campinas, v. 10, n. 2, maio/ago. 1998. Disponível em: <http://periodicos.puccampinas.edu.br/seer/index.php/transinfo/article/view/1566/1539>. Acesso em: 18 nov. 2013. 
Breno Oliveira Nóbrega do Nascimento; Raimundo Nonato Ribeiro dos Santos; Isa Maria Freire

Gestão da informação no blog de olho na Cl

MARCHIORI, Patricia Zeni. A ciência e a gestão da informação: compatibilidades no espaço profissional. Ciência da Informação,Brasília, v. 31, n. 2, maio/ago. 2002.

Disponível em: <http://revista.ibict.br/ciinf/index.php/ciinf/article/view/159/138>.

Acesso em: 18 nov. 2013.

MCGEE, James; PRUSAK, Laurence. Gerenciamento estratégico da informação: aumente a competitividade e a eficiência de sua empresa utilizando a informação como uma ferramenta estratégica. 5.ed. Rio de Janeiro: Campus, 1994.

NIELSEN, Michael. Information aggregators. 2007. Disponível em: <http://michaelnielsen.org/blog/information-aggregators/>. Acesso em: 18 nov. 2013.

PESQUISA BRASILEIRA EM CIÊNCIA DA INFORMAÇÃO E BIBLIOTECONOMIA PBCIB. De olho na Cl. Blog PBCIB. Paraíba, 3 ago. 2010. Disponível em: <http://www.deolhonaci.com>. Acesso em: 19 nov. 2013.

SARACEVIC, Tefko. Ciência da informação: origem, evolução e relações.

Perspectivas em Ciência da Informação, Belo Horizonte, v. 1, n. 1, p. 41-62, jan./jun. 1996. Disponível em:

<http://portaldeperiodicos.eci.ufmg.br/index.php/pci/article/view/235/22>. Acesso em: 18 nov. 2013.

ZIMAN, John. Conhecimento público. Belo Horizonte: Itatiaia; São Paulo: USP, 1979.

\section{Title}

Information management in Blog De Olho $\mathrm{Na} \mathrm{Cl}$

\section{Abstract}

Introduction: The mass media, digital technologies and the Internet have transformed the daily lives of humans. With its popularity, started to use these means of communication available to share information both in real environment and in virtual space, dealing with aspects of production and communication of information. These questions relate to the theme of information management.

Objective: Analyzes the blog De Olho $\mathrm{Na} \mathrm{Cl}$ from the perspective of management information and studies on the information aggregates.

Methodology: Conducted a documentary survey the literature in Information Science on the studies developed on the information aggregates. Analyzes the blog De Olho $\mathrm{Na} \mathrm{Cl}$ this perspective, aligned research information management developed in Information Science. Results: According to the survey, the blog $\mathrm{De}$ Olho $\mathrm{Na} \mathrm{Cl}$ acts as an information aggregate, fulfilling both functions indicated by the literature: the production and transfer of information. Conclusions: The information is a central point between Policy and Management in the government environment, institutional or virtual, considering initiatives to promote free access to information and use of free software. The blog $\mathrm{De} \mathrm{Olho} \mathrm{Na} \mathrm{Cl}$ is one such initiative, an information aggregate where the functions information production and information transfer 
Breno Oliveira Nóbrega do Nascimento; Raimundo Nonato Ribeiro dos Santos; Isa Maria

Freire

Gestão da informação no blog de olho na Cl

of harmonize and create opportunities for sharing new information. A virtuous cycle of search, production and distribution of raw materials more important in contemporary society: the information.

Keywords: Information management. Information aggregates. Communication of information.

\section{Título}

Gestión de la información em Blog De Olho Na Cl

\section{Resumen}

Introducción: Los medios de comunicación, las tecnologías digitales e Internet han transformado la vida cotidiana de los seres humanos. Con su popularidad, comenzamos a utilizar estos medios de comunicación disponibles para compartir información, tanto en el ambiente real y en el espacio virtual, que trata de los aspectos de la producción y comunicación de información. Estas preguntas se relacionan con el tema de la gestión de la información.

Objetivo: Analizar lo Blog De Olho $\mathrm{Na} \mathrm{Cl}$ desde la perspectiva de la gestión de la información y estudios sobre los agregados de información.

Metodología: Se realizó una encuesta documental de la literatura en ciencias de la información sobre los estudios realizados sobre los agregados de información. Así, se analiza el blog De Olho $\mathrm{Na} \mathrm{Cl}$ esta perspectiva, alineado la investigación em gestión de la información desarrollado en Ciencias de la Información.

Resultados: Según la encuesta, el blog De Olho $\mathrm{Na} \mathrm{Cl}$ actúa como un agregado de la información, el cumplimiento de ambas funciones indicadas por la literatura: la producción y la transferencia de información.

Conclusiones: La información es un punto central entre la política y la gestión en el entorno gubernamental, institucional o virtual, teniendo en cuenta las iniciativas que promuevan el libre acceso a la información y el uso de software libre. El blog De Olho $\mathrm{Na} \mathrm{Cl}$ es una de estas iniciativas, un agregado de funciones en la producción de información y la transferencia de información armonizar y crear nuevas oportunidades para el intercambio de información. Un círculo virtuoso de la búsqueda, producción y distribución de la materia primas más importantes en la sociedad contemporánea: la información.

Palabras clave: Gestión de la información. Agregados de la información. Comunicación de la información.

Recebido em: 30.07 .2013

Aceito em: 01.12.2013 